\title{
Clinical features of sarcoidosis in relation to HLA distribution and HLA-DRB3 genotyping by PCR-RFLP
} Mami Ishihara, Takako Ishida, Nobuhisa Mizuki, Hidetoshi Inoko, Hitoshi Ando,
Shigeaki Ohno
HLA alleles and diseases. The aetiological factors of sarcoidosis are unknown although HLA is predisposed to the disease. Several investigators observed through serological typing that the frequencies of HLA-B8-DR3, ${ }^{5}$ -DR5, ${ }^{6}$ and -DR6 were increased in white patients. On the other hand, we have found by serological typing a significant association between HLA-DR52, -DR5, -DR6, and -DR8 and sarcoidosis in Japanese patients. ${ }^{8}$ Our genotyping studies using the polymerase chain reaction-restriction fragment length polymorphism (PCR-RFLP) also showed a positive association between sarcoidosis and the HLADRB1 genes in DR5, DR6, and DR8. ${ }^{9}$ However, the involvement of the HLA-DRB3 gene, which encodes the DR52 specificity, in the development of sarcoidosis remains unclear.

The HLA-DR region includes the common DRA and DRB1 genes, additionally with none or some of the DRB2, DRB3, DRB4, DRB5, DRB6, DRB7, DRB8, or DRB9 gene, ${ }^{10}$ depending on HLA haplotypes (Fig 1). Among them, DRB2, DRB6, DRB7, DRB8, and DRB9 are pseudogenes. The DR3, 5, 6, 8 group antigens (HLA-DR3, -DR5, -DR6, and -DR8.DR3 are very rare in the Japanese population) were considered to be linked to HLA-DR52 because anti-DR52 sera react against these antigen associated HLA-haplotypes. However, gene cloning analysis has revealed that only DR3, DR5, and DR6 completely correlated with the genetic composition of DR52: the DR region of these DR52 group haplotypes includes the DRA, DRB1, DRB2, DRB3, and DRB9 genes. The DRA gene, which encodes the DR52 $\alpha$ chain as well as the DR3, DR5, and DR6 chains, is not polymorphic. In contrast, the DRB1 gene is highly polymorphic and determines the DR3, DR5, and DR6 specificities. The DRB3 gene encodes the DR52 $\beta$ chain to specify the DR52 group by complexing with the $\mathrm{DR} \alpha$ chain. Linkage disequilibria are observed between the DRB1 and the DRB3 genes (Table 1). The DR8 haplotype also includes the DRA and DRB1 genes, thus determining DR8 specificity but does not contain the DRB3 gene. In this way, in the DR3, 5, 6, 8 group antigens, it has been established that DR8 is not linked to DR52. Positive reactivity against the DR8 haplotype by anti-DR52 sera has now been interpreted to be due to cross reaction or the presence of multispecific sera.

In the present study, we determined the genetic polymorphism of the DRB3 gene in chain reaction (PCR) based DNA typing technique, ${ }^{4}$ which is expected to facilitate a more detailed analysis of the association between

Immune responses are initiated when the $\mathrm{T}$ cell receptor recognises foreign or self triggered leucocyte antigen (HLA) class II molecules py the major histocompatibility $\mathrm{DR}, \mathrm{DQ}$, and DP, being composed of one and one $\beta$ chain. These polymorphic class II immune response ${ }^{1}$ and specify genetic determinants of the susceptibility to autoimmune disease. ${ }^{2} 3$ Recently, polymorphic class II 


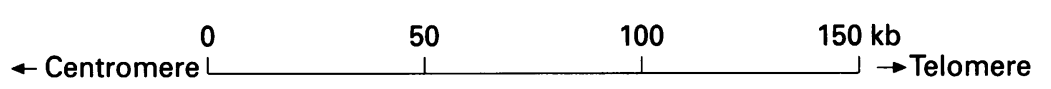
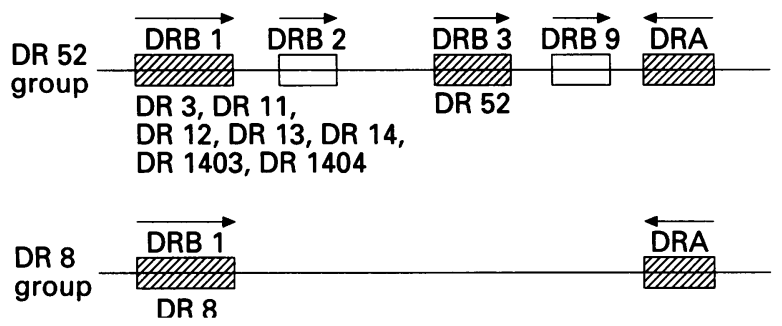

Figure 1 Gene structure of $H L A-D R B$ region. The DR52 group (DR3, DR5, and DR6) haplotype and the DR8 group haplotype are illustrated. In the other haplotypes, the structures of the DR8 gene region are slightly different. Thin arrows indicate the orientation of transcript $\left(5^{\prime}-3^{\prime}\right) . \square=$ expressed gene; $\square=$ pseudogene.

sarcoidosis using the PCR-RFLP method to confirm the primary association of the DRB1 gene with sarcoidosis. Further, to investigate the specific correlation of HLA antigens with clinical features, especially intraocular lesions in Japanese patients with sarcoidosis, the clinical features of patients with and without the DR3, 5, 6, 8 group antigens were compared.

\section{Patients and methods}

PATIENTS

Fifty six Japanese patients with sarcoidosis and with one of the DR3, 5, 6,8 group antigens and 21 patients without DR3, 5, 6, or 8 group antigens from department of ophthalmology, Japanese Red Cross Medical Center, between 1985 and 1993, were enrolled in this study. HLA-DR antigens were typed serologically using peripheral blood lymphocytes by the standard complement dependent micro lymphocyte toxicity assay. ${ }^{11}$ Since DR3 is very rare in Japanese, the 56 patients had only DR5, DR6, or DR8. The diagnosis of sarcoidosis was based on the histological and immunological studies of transbronchial lung biopsy (TBLB), peripheral lymph node biopsy, skin biopsy, and/or bronchoalveolar lavage (BAL). Patients ranged in age at the onset of the

Table 1 Linkage disequilibrium in HLA class II alleles in fapanese

\begin{tabular}{llll}
\hline$D R B 1$ & $D R B 3$ & $D Q A 1$ & $D Q B 1$ \\
\hline 1101 & 0202 & 0501 & 0301 \\
1101 & 0202 & 0501 & 0402 \\
1101 & 0202 & 0501 & 0302 \\
1201 & 0101 & 0501 & 0301 \\
1201 & 0101 & 0301 & 0301 \\
1201 & 0101 & 0301 & 0303 \\
1201 & 0101 & 0301 & 0302 \\
1201 & 0202 & 0601 & 0301 \\
1202 & 0301 & 0601 & 0301 \\
1301 & 0101 & 0103 & 0603 \\
1301 & 0202 & 0103 & 0603 \\
1302 & 0301 & 0102 & 0604 \\
1302 & 0301 & 0102 & 0605 \\
1401 & 0202 & 0101 & 0502 \\
1401 & 0202 & 0101 & 0503 \\
1403 & 0101 & 0501 & 0301 \\
1405 & 0202 & 0101 & 0503 \\
1406 & 0101 & 0501 & 0301 \\
1406 & 0202 & 0501 & 0301 \\
1407 & 0202 & 0101 & 0503 \\
1408 & 0202 & 0101 & 0503 \\
\hline
\end{tabular}

Table 2 Correlation between the DR3, 5, 6, 8 group antigens and intraocular lesions

\begin{tabular}{|c|c|c|}
\hline Intraocular lesions & $\begin{array}{l}D R 3,5,6,8 \\
\text { group (+) } \\
(n=56)\end{array}$ & $\begin{array}{l}D R 3,5,6,8 \\
\text { group (-) } \\
(n=21)\end{array}$ \\
\hline $\begin{array}{l}\text { Granulomatous iridocyclitis } \\
\text { Perivasculitis } \\
\text { High intraocular pressure } \$ \\
\text { Chorioretinitis } \\
\text { Vitreous opacities } \dagger\end{array}$ & $\begin{array}{l}30(52 \cdot 6 \%) \\
23(41 \cdot 2 \%)^{(1)} \\
20(35 \cdot 7 \%)^{(2)} \\
36(64 \cdot 3 \%) \\
24(42 \cdot 9 \%)\end{array}$ & $\begin{array}{l}15(71 \cdot 4 \%) \\
17(81 \cdot 0 \%) \\
10(45 \cdot 5 \%) \\
16(76 \cdot 2 \%) \\
14(66 \cdot 7 \%)\end{array}$ \\
\hline $\begin{array}{l}\text { Optic nerve lesion and/or } \\
\text { macular lesion } \ddagger \\
\text { Chorioretinal scarring }\end{array}$ & $\begin{array}{c}8(14 \cdot 3 \%)^{(3)} \\
20(35 \cdot 7 \%)\end{array}$ & $\begin{array}{r}8(38 \cdot 1 \%) \\
13(61.9 \%)\end{array}$ \\
\hline
\end{tabular}

*Granulomatous iridocyclitis with mutton fat keratic

precipitates and/or iris nodules, trabecular nodules, tent-like peripheral anterior synechiae.

$\oint$ High intraocular pressure or secondary glaucoma.

†Vitreous opacities forming a 'snowball', 'string of pearls', or 'snow banking'.

$\ddagger$ Optic nerve lesion includes papilloedema or neuritis, and macular lesion includes macular oedema or cystoid macular oedema.

p Values were used to compare DR3, 5, 6, 8 group (+)

patients $v$ DR3, 5, 6, 8 group $(-)$ patients; $p$ values are shown when $\mathrm{p}<0.05$.

(1) $\chi^{2}=8.02, \mathrm{p}<0.01, \mathrm{RR}=6.1$

(2) $\chi^{2}=4 \cdot 75, \mathrm{p}<0 \cdot 05, \mathrm{RR}=3 \cdot 6$

(3) $\chi^{2}=6.85, \mathrm{p}<0.02, \mathrm{RR}=3 \cdot 7$.

disease from 15 to 68 years, with a mean age of $34 \cdot 1$ years. The duration of the disease ranged from 2 to 39 years, with the average being 13.3 years. Fifty eight of the patients were women. Sixty five patients had intraocular lesions in their clinical course and most of them had at least two different kinds of intraocular lesions as described below. At the time of the investigation, 35 patients exhibited chronic active inflammation while the remaining 30 patients had no inflammation.

Intraocular lesions in patients with sarcoidosis were divided into seven categories and are listed in Table 2: (1) granulomatous iridocyclitis, (2) retinal perivasculitis, (3) high intraocular pressure or secondary glaucoma, (4) chorioretinitis, (5) vitreous opacities, (6) optic nerve lesion and/or macular lesion, or (7) chorioretinal scarring. Clinical characteristics, including sex, mean age at onset, mean duration of the disease, presence of intraocular lesions, number of intraocular lesions (shown

Table 3 Correlation between the DR3, 5, 6, 8 group antigens and clinical features

\begin{tabular}{|c|c|c|}
\hline & $\begin{array}{l}\text { DR3, 5, 6, } 8 \\
\text { group }(+)(n=56)\end{array}$ & $\begin{array}{l}D R 3,5,6,8 \\
\text { group }(-)(n=21)\end{array}$ \\
\hline \multicolumn{3}{|l|}{ Sex } \\
\hline Male & $13(23 \cdot 2 \%)$ & $6(28 \cdot 6 \%)$ \\
\hline Female & $43(76 \cdot 8 \%)$ & $15(71 \cdot 4 \%)$ \\
\hline \multicolumn{3}{|c|}{ Age at onset (years) } \\
\hline Mean & $31 \cdot 2$ & $42 \cdot 0$ \\
\hline$<40$ & $42(75 \cdot 0 \%)^{\star}$ & $10(47 \cdot 6 \%)$ \\
\hline$\geqslant 40$ & $14(25 \cdot 0 \%)$ & $11(52 \cdot 4 \%)$ \\
\hline \multicolumn{3}{|c|}{ Duration of disease (years) } \\
\hline Mean & $13 \cdot 5$ & $12 \cdot 9$ \\
\hline$<10$ & $16(26 \cdot 8 \%)$ & $7(33 \cdot 3 \%)$ \\
\hline$\geqslant 10$ & $40(73 \cdot 2 \%)$ & $14(66 \cdot 7 \%)$ \\
\hline \multicolumn{3}{|c|}{ Ocular involvement } \\
\hline$(+)$ & $45(80 \cdot 4 \%)$ & $20(95 \cdot 2 \%)$ \\
\hline \multirow{2}{*}{\multicolumn{3}{|c|}{ Number of ocular lesions }} \\
\hline & & \\
\hline $\begin{array}{l}\text { Average } \\
<4\end{array}$ & $\begin{array}{l}2 \cdot 9 \\
38\end{array}$ & $4 \cdot 8$ \\
\hline $\begin{array}{l}<4 \\
\geqslant 4\end{array}$ & $\begin{array}{l}38(67 \cdot 9 \%) \S \\
18(32 \cdot 1 \%)\end{array}$ & $\begin{array}{r}5(23 \cdot 8 \%) \\
16(76 \cdot 2 \%)\end{array}$ \\
\hline \multicolumn{3}{|c|}{ Lung involvement } \\
\hline $\begin{array}{l}(+) \\
(-)\end{array}$ & $\begin{array}{r}50(89 \cdot 3 \%) \\
6(10 \cdot 7 \%)\end{array}$ & $\begin{aligned} 18(85 \cdot 7 \%) \\
3(14.3 \%)\end{aligned}$ \\
\hline
\end{tabular}

p Values were used to compare DR3, 5, 6, 8 group ( + ) patients $v$ DR3, 5, 6, 8 group (-) patients; $p$ values are shown when $p<0.05$. ${ }^{\star} \chi^{2}=4.05, \mathrm{p}<0.05, \mathrm{RR}=3.3$.

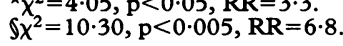


in Table 2), and lung involvement are summarised in Table 3 . These clinical factors were compared between those with and without the DR3, 5, 6, 8 group antigens.

\section{HLA-DRB3 GENOTYPING BY THE PCR-RFLP METHOD}

Genomic DNAs of 47 patients with sarcoidosis who have either DR5 or DR6 and of 82 healthy controls who have either DR5 or DR6 were purified from peripheral blood cells by the proteinase K-phenol extraction method. ${ }^{12}$ The PCR-RFLP method was employed for HLA-DRB3 genotyping as described before. ${ }^{4}$ Briefly, 0.2-0.5 $\mu \mathrm{g}$ genomic DNA was subjected to 30 cycles of amplification (1 minute at $96^{\circ} \mathrm{C}, 1$ minute at $54^{\circ} \mathrm{C}$, and 2 minutes at $72^{\circ} \mathrm{C}$ ) by automated PCR thermal sequencer (Iwaki Glass Inc) using a pair of primers specific for the second exon of the HLA-DRB3 gene: 5'-primer: 5'-CCCAGCACGTTTCTTGGAGCT- 3 ' and 3'-primer: 5'-CCGCTGCACTGTGAAGCTCT-3'. The resulting fragment was $271 \mathrm{bp}$ in size. Three restriction enzymes, Kpn I, Hinf I, and $\mathrm{Hph} \mathrm{I}$, were used to discriminate between the four alleles of the DRB3 gene, DRB $3^{\star} 0101$, 0201, 0202, and 0301.

\section{STATISTICAL ANALYSIS}

The statistical significance of the association of DRB3 alleles with sarcoidosis was evaluated by Fisher's exact p test with Yates's correction. A level of $p<0.05$ was accepted as statistically significant. Relative risk (RR) was calculated from the cross product ratio of the entries in the $2 \times 2$ table.

\section{Results}

\section{HLA-DRB 3 GENOTYPING}

HLA-DRB3 genotypes of patients with sarcoidosis and healthy controls were determined according to the RFLP pattern generated after restriction enzyme digestion of the PCR amplified DRB3 gene product. The results are summarised in Table 4 . Our data indicated that the frequency of HLA-DRB $3^{\star} 0101$ was increased significantly $\left(\chi^{2}=4.82, \mathrm{p}<0.05\right.$, $R R=2 \cdot 6$ ) in patients compared with healthy controls. Further, the frequency of HLA$\mathrm{DRB}^{\star}{ }^{\star} 0202$ was high and that of $\mathrm{DRB} 3{ }^{\star} 0301$ was low relative to healthy controls, although these differences did not reach statistical significance. These results confirmed our previous conclusion of the primary association of the DRB1 gene encoding the DR5, DR6,

Table 4 Frequencies of HLA-DRB3 alleles

\begin{tabular}{llllll}
\hline Allele & $\begin{array}{l}\text { Controls } \\
n=82(\%)\end{array}$ & $\begin{array}{l}\text { Patients } \\
n=47(\%)\end{array}$ & $\chi^{2}$ & $\begin{array}{l}\text { Value } \\
\text { Valative }\end{array}$ & $\begin{array}{l}\text { Rel } \\
\text { risk }\end{array}$ \\
\hline 0101 & $17(20 \cdot 7)$ & $19(40 \cdot 4)$ & 4.82 & $<0.05$ & 2.6 \\
0201 & $0(0)$ & $0(0)$ & & & \\
0202 & $35(42 \cdot 7)$ & $26(55 \cdot 3)$ & & & \\
0301 & $32(39 \cdot 0)$ & $10(21 \cdot 3)$ & & & \\
\hline
\end{tabular}

$\mathrm{p}$ Values were used to compare patients $v$ controls; $\mathrm{p}$ values are shown when $\mathrm{p}<0.05$. and DR8 antigen specificity with sarcoidosis.

CORRELATIONS BETWEEN 'DR3, 5, 6, 8 GROUP' ANTIGENS AND CLINICAL CHARACTERISTICS, INCLUDING INTRAOCULAR LESIONS

The correlations among the DR3, 5, 6, 8 group antigens and intraocular lesions are summarised in Table 2 . There were significantly decreased frequencies of the DR3, 5, 6, 8 group antigens in the patients with retinal perivasculitis $(p<0.01)$, high intraocular pressure (or secondary glaucoma) $(p<0.05)$, and an optic nerve and/or macular lesion $(\mathrm{p}<0.02)$.

The correlations among the DR3, 5, 6, 8 group antigens and other clinical features are shown in Table 3. Patients with a DR5, 6 , or 8 antigen were significantly younger at the onset of the disease (less than 40 years old, $\mathrm{p}<0.05$ ) than those without a DR5, 6 , or 8 antigen. The average number of intraocular lesions was $2 \cdot 9$ in the DR3, $5,6,8$ group antigen positive patients and 4.8 in the DR3, 5, 6, 8 group antigen negative patients. Patients with a DR5, 6 , or 8 antigen had significantly fewer intraocular lesions (fewer than four intraocular lesions, $p<0.005)$ than did those without a DR5, 6 , or 8 antigen. No significant difference in any other clinical variable, including sex, duration of disease, rate of intraocular involvement, and lung involvement, was noted between the two groups.

\section{Discussion}

We noted previously that the HLA-DR5-, -DR6-, and -DR8-DRB1 molecules confer primary susceptibility to sarcoidosis in Japanese patients. ${ }^{89}$ However, about $21 \%$ of patients with sarcoidosis have been found to be DR3, $5,6,8$ group antigen negative. Further, no difference in the HLA-DRB1 allele frequency was observed between patients and healthy controls who did not have any DR3, 5, 6, 8 group antigen (unpublished data). In the present study, we investigated whether there was any clinical difference between patients with and without the DR3, 5, 6, 8 group antigens and found that the DR3, 5, 6, 8 group antigens are associated with early onset of sarcoidosis (younger than 40 years old) and also with fewer intraocular lesions (shown in Table 3). HLA-DR3 was shown to be associated with a good prognosis in England. ${ }^{13}$ In Japan, an association was observed between HLA-DR5, good prognosis, and early onset of sarcoidosis. ${ }^{14}$ Also, advanced stage as well as resistance to treatment was associated with absence of HLA-DR52. ${ }^{15}$ These results are consistent with our present data. On the other hand, there was no report of any correlation between HLA and intraocular lesions. Significantly decreased frequencies of the DR3, 5, 6, 8 group antigens were observed in the patients with retinal perivasculitis, high intraocular pressure (or secondary glaucoma), and an optic nerve and/or macular lesion, suggesting that patients without a DR5, 6 , or 8 antigen should be followed carefully for the 
development of complications such as secondary glaucoma, neuritis, and macular oedema that may cause a visual disturbance. It remains unclear why the patients who do not carry any DR3, 5, 6, 8 group antigen develop the disease. We suppose that the foreign or self antigen triggering sarcoidosis in two groups is different or that it has the ability to be recognised by different sites in the polymorphic domains of HLA antigens.

DRB3 genotyping of patients with sarcoidosis was performed by the PCR-RFLP method in order to determine which the primary association with sarcoidosis is either DRB1 locus or DRB3 locus. The frequency of HLA$\mathrm{DRB}^{\star}{ }^{\star} 0101$ was increased in patients compared with healthy controls. HLA-DR52 was classified into four suballeles - DRB3 ${ }^{\star} 0101$, 0201, 0202, and 0301.16 In the Japanese population, HLA-DRB3*0101 is known to be in linkage disequilibrium with DRB1 ${ }^{\star} 1201-\mathrm{DQA}^{\star}{ }^{\star} 0501$ (DQA1*0301), $-\mathrm{DQB1}{ }^{\star} 0301$ (DQB1*0303), and DRB1* 1403-DQA1*0501-DQB1*0301. ${ }^{16}$ Similarly, HLA-DRB ${ }^{\star} 0202$ is in linkage disequilibrium with $\mathrm{DRB} 1{ }^{\star} 1101-\mathrm{DQA1}{ }^{\star} 0501-\mathrm{DQB} 1{ }^{\star} 0301$, $\mathrm{DRB} 1$ * $1401-\mathrm{DQA} 1{ }^{\star} 0101-\mathrm{DQB} 1{ }^{\star} 0502$ (DQB1*0503), DRB1*1406-DQA1*0501DQB $1{ }^{\star} 0301$, and HLA-DRB ${ }^{\star} 0301$ with $\mathrm{DRB}^{\star}{ }^{\star} 1202-\mathrm{DQA} 1{ }^{\star} 0601-\mathrm{DQB1}{ }^{\star} 0301$, and DRB $1{ }^{\star} 1302-\mathrm{DQA} 1{ }^{\star} 0102-\mathrm{DQB} 1{ }^{\star} 0604$. $\mathrm{DRB}^{\star} 0201$ is a very rare allele in Japanese. ${ }^{16}$ These tight linkage disequilibria between the DRB1-DQA1-DQB1 and DRB3 alleles make it difficult to determine the primary association among the disease associated DRB1-DQA1DQB1-DRB3 haplotypes.

On the basis of the present results, two hypotheses can be proposed to explain the susceptibility to sarcoidosis at the molecular level. The first is that the amino acid sequence specific and common to the HLA-DR5-, -DR6-, and -DR8-associated alleles in the first domain of the DRB1 gene is primarily responsible for the susceptibility to sarcoidosis, as hypothesised in our previous paper. ${ }^{89} \mathrm{An}$ alternative model is that $\mathrm{DRB}^{\star}{ }^{\star} 0101$ is a primary susceptibility gene which controls the development of sarcoidosis, indicating that specific amino acid residues for this DRB3 allele may be responsible for the pathogenesis of the disease. Unfortunately, however, this hypothesis does not explain why the frequency of DR8 (DRB1*08), which is known to lack the DRB3 gene, ${ }^{10}$ was significantly higher in our patients. ${ }^{89}$ The significantly increased frequency of $\mathrm{DRB}^{\star} 0101$ may represent linkage disequilibrium with the DR5- and DR6-associated DRB1 alleles as described above. Therefore, it is unlikely that the HLADRB3 (HLA-DR52) gene is a primary determinant of the efficiency of binding by a disease specific antigen and that it controls the susceptibility to sarcoidosis. This confirms that our previous result demonstrating that the HLA-alleles association in sarcoidosis is due to the DRB1 locus rather than the DRB3 locus.

1 Sasazuki T, Nishimura Y, Muto $M$, Ohta N. HLA-linked gene controlling the immune response and disease susceptibility. Immunol Rev 1983; 70: 51-75.

2 Tiwari JL, Terasaki PL. HLA and disease associations. New York: Springer-Verlag, 1986.

3 Todd JA, Acha-Orbea Bell J, Chao N, Fronek Z, Jacob $\mathrm{CO}$, et al. A molecular basis for MHC class-associated autoimmunity. Science 1989; 240: 1003-9.

4 Inoko H, Ota M. PCR-RFLP. In: Hui KM, Bidwell JL, eds. Handbook of HLA typing techniques 1993. Boca Raton: CRC Press, 1993: 9-70.

5 Hedfors EVA, Lindstorni F. HLA-B8/DR3 in sarcoidosis. Tissue Antigens 1983; 22: 200-3.

6 Nowack D, Goebel KM. Genetic aspects of sarcoidosis. Class II histocompatibility antigens and a family study. Arch Intern Med 1987; 147: 481-3.

7 Odum N, Milman N, Jakobsen BK, Georgssen J, Svejgaard A. HLA class II (DR, DQ, DP) in patients with sarcoidosis: evidence of an increased frequency of DR6. Exp Clin Immunogenet 1991; 8: 227-32.

8 Ishihara $M$, Ohno $S$, Ishida $T$, Kagiya $M$, Ando $H$, Inoko $H$. Analysis of susceptibility genes in sarcoidosis. $\mathcal{f} \mathcal{f p}_{p n}$ Ophthalmol Soc 1994; 98: 80-5.

9 Ishihara $M$, Ohno S, Ishida T, Ando H, Naruse T, Nose $\mathrm{Y}$, Inoko $\mathrm{H}$. Molecular genetic studies of HLA class II alleles in sarcoidosis. Tissue Antigens 1994; 43: 238-41.

10 Bodmer JG, Marsh SGE, Albert FD, Bodmer WF, Dupont $\mathrm{B}$, Erlich DA, et al. Nomenclature for factors of HLA system, 1991. Tissue Antigens 1992; 39: 161-73.

11 Terasaki PI. Cytotoxicity technique. In: Brand DL, Ray JG Jr, eds. Manual of tissue typing techniques. Bethesda, Maryland: National Institutes of Health, 1970: 42-5.

12 Inoko $H$, Ando $A$, Ito $M$, Tsuji $K$. Southern hybridization of DNA polymorphism in the HLA-D region. Hum Immunol 1986; 16: 304-13.

13 Gardner J, Kennedy H, Hamblin A, Jones E. HLA associations in sarcoidosis: a study of two ethnic groups. Thorax 1984; 37: 19-22.

14 Ina $Y$, Takada $K$, Yamamoto $M$, Morishita $M$, Senda $Y$, Torii Y. HLA and sarcoidosis in the Japanese. Chest 1989; 95: 1257-61.

15 Kunikane $H$, Abe S, Tsuneta $Y$, Nakayama T, Tajima $Y$, Misonou J, et al. Role of HLA-DR antigens in Japanese patients with sarcoidosis. Am Rev Resp Dis 1987; 135: 688-91.

16 Imanishi T, Akaza T, Kimura A, Tokunaga K, Gojobori T. Allele and haplotype frequencies for HLA and complement loci in various ethnic groups. In: Tsuji K, Aizawa M, Sasazuki T, eds. HLA 1991, vol 1. New York: Oxford University Press, 1992: 1065-220. 